九州大学学術情報リポジトリ

Kyushu University Institutional Repository

\title{
Studies on Matter Production in Sweet Potato Plants : 1. The Characteristics of Dry Matter and Yield Production under Field Conditions
}

Agata, Waichi

Laboratory of Crop Husbandry, Faculty of Agriculture, Kyushu University

Takeda, Tomoshiro

Laboratory of Crop Husbandry, Faculty of Agriculture, Kyushu University

https://doi.org/10.5109/23759

出版情報: 九州大学大学院農学研究院紀要. 27 (1/2)，pp.65-73，1982-10. Kyushu University バージョン：

権利関係 : 


\title{
Studies on Matter Production in Sweet Potato Plants \\ 1. The Characteristics of Dry Matter and Yield Production under Field Conditions
}

\author{
Waichi Agata and Tomoshiro Takeda \\ Laboratory of Crop Husbandry, Fitculty of Agriculture, \\ Kyushu University 46-02, Fukuoka 812 \\ (Received June 17, 1982)
}

\begin{abstract}
This investigation was conducted to elucidate the characteristics of dry matter and yield production of sweet potatoes (Ipomoea batatas (L.) Lam.) under field conditions. Two cultivars (Koganesengan and Minamiyutaka) were used as materials. The materials were grown under ordinary field cultivating conditions. Growth analysis was periodically done throughout the whole growth duration. Further, the relations of climatic factors to dry matter production and yield were made by correlation analysis. Dry weight of total and tuberous root (yield) of Koganesengan were $2,047 \mathrm{~g} \mathrm{DW} / \mathrm{m}^{2}$ and $1,754 \mathrm{~g} \mathrm{DW} / \mathrm{m}^{2}$, respectively. These values were larger than those of Minamiyutaka. Its harvest index was $84.6 \%$. The growth period of this crop was divided into two from the variation of LAI with growth. The first half period was the stage of LAI increase and the second half was that of maintaining matured LAI (canopy). In both cultivars the maximum LAI reached about 5.0 and optimum LAI was 3.67. Further CGRmax was $20.66 \mathrm{~g} \mathrm{DW} / \mathrm{m}^{2}$ /day. CGR in the first half period depended highly on LAI through mean air temperature and in the second half period on NAR through mean solar radiation. Yield growth rate (YGR) in the second half period was also more influenced by NAR through mean solar radiation than air temperature. Lower air temperature, within favourable range of growing temperature, was good for YGR.
\end{abstract}

\section{INTRODUCTION}

The sweet potatoes produce the highest amount of calories per unit land area among useful crops in Japan. Therefore, sweet potatoes have been grown as one of the most important crops for food since 18th century. Recently, this crop is also considered to be most promising for industrial raw material with special reference to biomass energy. From the importance of this crop, a lot of research on cultivation method has been done since the Meiji era in Japan, but not much research has been made from the viewpoint of matter production (Boysen-Jensen, 1932). Tsuno and Fujise (1965) made the first studies based on the matter production, and they also provided the theoretical foundation for its cultivation method. In their study, however, the relation between climatic factors and dry matter production throughout the growth period were not clarified enough.

This investigation was carried out to make clear the characteristics of dry 
matter and yield production during the whole growth period in relation to climatic factors, based on growth analysis (Watson, 1952).

\section{MATERIALS AND METHODS}

Two cultivars (Koganesengan and Minamiyutaka) of sweet potato plant (Ipomoea batatas (L.) Lam.) were used in this experiment. These cultivars are the recommended varieties for food and industrial raw material in Japan. Nurscry stocks of both cultivars were obtained from the Kyushu National Agricultural Experiment Station, Kumamoto. The material plants were grown on the experimental field inside the campus of Kyushu University under standard cultural conditions from June 11 (planting date) to November 14 (harvesting date), 1979. Basal dressing of 6-6-19 (N-P-K) $\mathrm{kg} / 10$ a was applied 10 days before planting. Planting densities of two cultivars were same and they were 4,938 plants per 10 a (one plant per $45 \mathrm{~cm} \times 45 \mathrm{~cm}$ ). About 2 a was used for this experiment. From August to September, irrigation was carried out frequently to minimize moisture stress.

During the growing period, sampling was carried out 10 times at about two weeks interval. Number of plots sampled at each time were three. The sampled plots had a quadrat of $90 \mathrm{~cm} \times 90 \mathrm{~cm}$ and sampling was done at random.

Growth analysis followed Watson's method (Watson, 1952). Crop growth rate (CGR), net assimilation rate (NAR), maximum crop growth rate (CGR. max) and optimum leaf area index (Fopt) were calculated based on the data of dry weight and leaf area measured at each sampling time.

For the climatic factors such as air temperature, solar radiation and precipitation during the growing period, the measuring data of Fukuoka Meteorological Observatory Station in Fukuoka City were applied.

\section{RESULTS AND DISCUSSION}

\section{General conditions of climatic and growth}

The mean daily air temperature, mean daily solar radiation and the amount of precipitation in each growth period from June 11 to November 14 in 1979 are given in Table 1. Mean values of air temperature and solar radiation during the whole growth period were $24.2 \pm 3.6^{\circ} \mathrm{C}$ and $319 \pm 85 \mathrm{cal} / \mathrm{m}^{2}$ per day, respectively. Both factors tended to increase until the end of July and then to decrease until November. In the case of radiation, however, many fluctuations were noticed in the latter half period. The amount of precipitation differed in each growth period. Generally speaking, climatic conditions in 1979 were quite favourable for sweet potatoes growth. Therefore, the yield showed a higher level.

\section{Total and tuberous root dry weight}

Changes of total and tuberous root dry weight of Koganesengan with growing time are shown in Fig. 1. Those of Minamiyutaka were almost simi. 
Table 1. Mean daily air temperature, mean daily solar radiation and precipitation at each growth period of sweet potato (1979 in Fukuoka).

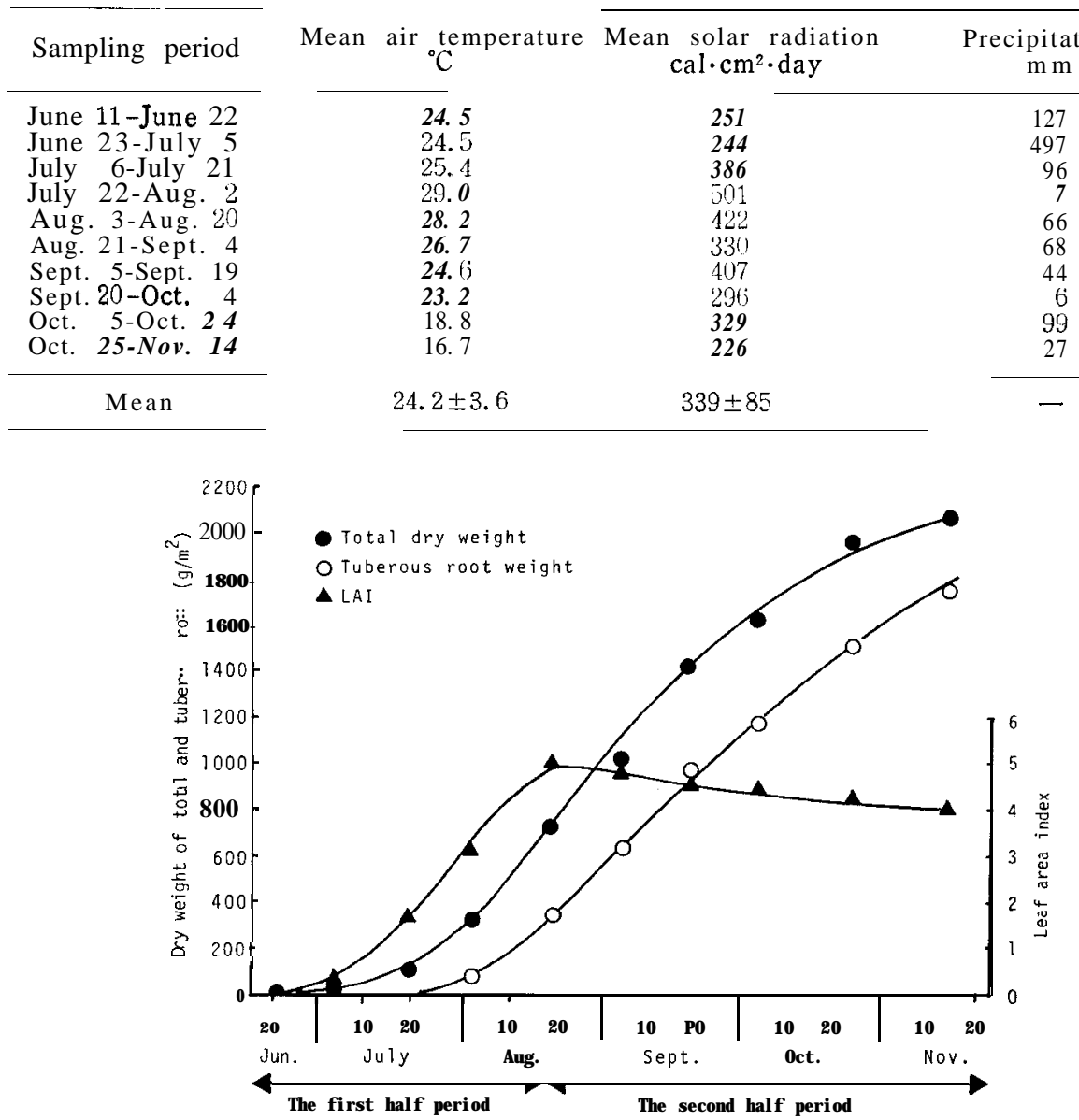

Fig. 1. Changes of total dry weight, tuberous root dry weight (yield) and leaf area index (LAI) with growing time under field conditions (cultivar: Koganesengan).

lar to Koganesengan. The total weight (W) showed the typical sigmoid growth curve. The highest values at harvesting time of Koganesengan and of Minamiyutaka were 2,047 $\mathrm{g} \mathrm{DW} / \mathrm{m}^{2}$ and $1,859 \mathrm{~g} \mathrm{DW} / \mathrm{m}^{2}$, respectively.

On the other hand, the formation of tuberous root started at 30-35 days after planting and its dry weight (yield) increased almost linearly until harvesting. The yield of Koganesengan at harvesting time was $1,754 \mathrm{~g} \mathrm{DW} / \mathrm{m}^{2}$, and that of Minamiyutaka was $1,431 \mathrm{~g} \mathrm{DW} / \mathrm{m}^{2}$. These values were larger cornpaired with that of Tsuno and Fujise (1965). The reason for this may be that the growth period was longer and climatic conditions were more favourable in this experiment. 


\section{Leaf area index}

Changes of leaf area index of Koganesengan with growth time is also shown in Fig. 1. After planting, LAI increased rapidly until early August and then it decreased gradually towards November. But LAI above 4 was kept until November in both cultivars. Based on LAI, the growth period is divided into two. The first half period is the stage of increasing LAI and the second half period is the stage of maintaing matured LAI.

\section{The ratio of dry weight of each plant part}

Fig. 2 shows changes of the dry weight ratio of each plant part of Koganesengan with growth time. The ratio of leaf to total weight is larger in the first half than the second half period. On the other hand, that of tuber weight is a contrast to this. Further, the ratios of tuber weight (yield) to total weight, that is, harvest index (Donald, 1962) were $84.6 \%$ in Koganesengan and $77.0 \%$ in Minamiyutaka.

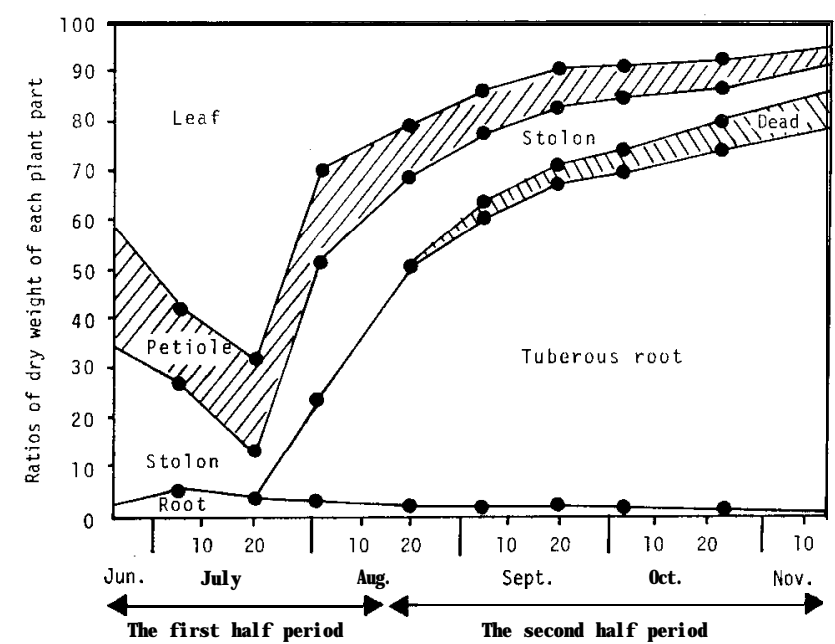

Fig. 2. Changes in ratios of dry weight of each plant part during the growth period (cultivar: Koganesengan).

\section{Growth analysis}

Growth analysis was carried out based on the data of total dry weight and LAI in each growth period of two cultivars. The results of Koganesengan are shown in Fig. 3. CGR increased exponentially until early August, showing a pattern similar to the increasing trend of LAI. Then CGR varied irregularly until November, that is, peaks of CGR were noticed in September and October, respectively. Whereas, NAR which is a component of CGR reached a peak at the end of July. Thereafter, it showed a pattern similar to CGR until harvesting time.

The changes of CGR, LAI and NAR during the growth period suggest that CGRs before and early August depend mainly on LAI and NAR, respectively. 


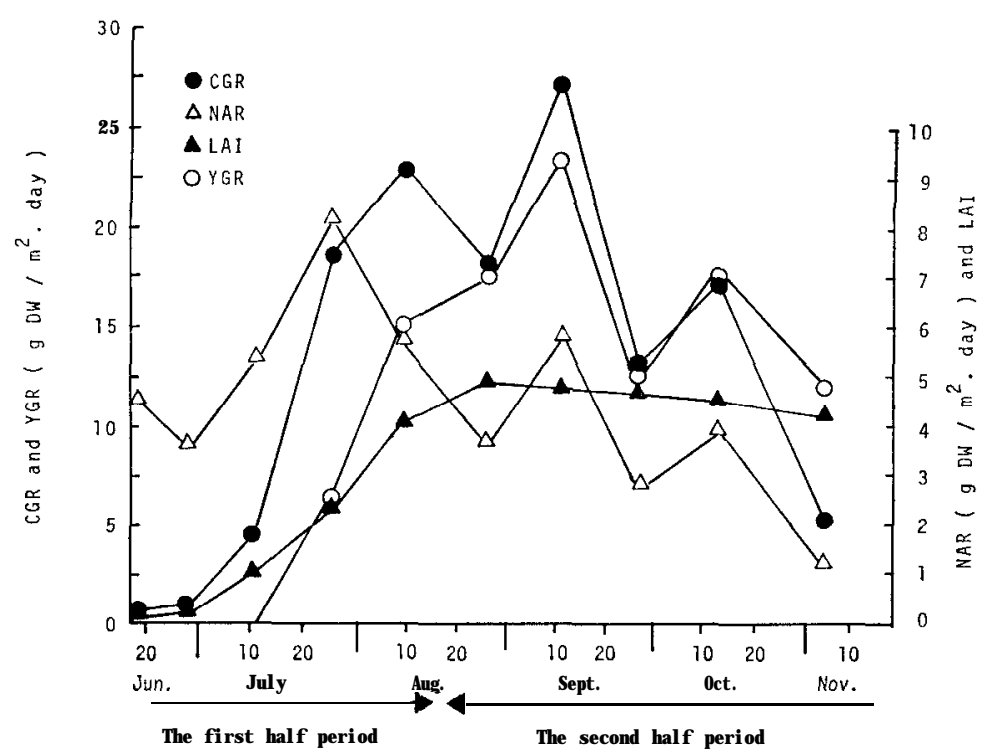

Fig. 3. Changes of crop growth rate (CGR), net assimilation rate (NAR) leaf area index (LAI) and tuberous growth rate (YGR) during growth period (cultivar : Koganesengan).

Table 2. Correlation coefficients of crop growth rate (CGR) with leaf area index (LAI) and net assimilation rate (NAR) at the first half and the second half of growth period.

\begin{tabular}{|c|c|c|c|c|c|}
\hline \multirow{2}{*}{\multicolumn{2}{|c|}{ Varieties }} & \multirow{2}{*}{$\begin{array}{l}\text { The first } \\
\text { LAI }\end{array}$} & \multirow{2}{*}{$\frac{\text { half period }}{\text { NAR }}$} & \multicolumn{2}{|c|}{ The second half period } \\
\hline & & & & LAI & NAR \\
\hline Koganesengan & CGR & $0.975^{* * *}$ & 0.612 & 0.718 & $0.985 * *$ \\
\hline Minamiyutaka & CGR & $0.959 * *$ & 0.095 & 0.742 & $0.995^{* *}$ \\
\hline
\end{tabular}

$* *$ Significant at $1 \%$ level.

Thus, the analyses as to the correlations of CGR with NAR and LAI at the first and second half periods were made using the data obtained from two cultivars. As shown in Table 2, CGR in the first half period correlated highly with LAI, but not with NAR. Such a result has been reported in a lot of crop populations (Takeda, 1961; Murata, 1961; Donald, 1963; Tsuno and Fujise, 1965; Buttery, 1969; Tateno and Ojima, 1973; Nakaseko and Gotoh, 1981).

As LAI - NAR and LAI - CGR relations show the characteristics of dry matter production under field conditions, the relations of LAI with NAR and CGR were analyzed using the data of two cultivars obtained the period from July 22 to September 4, 1979. In this period, the variations of climate and plant growth were very small. The relations of LAI with NAR and CGR were very close as shown in Fig. 4, that is, the former showed a linear relation and the 


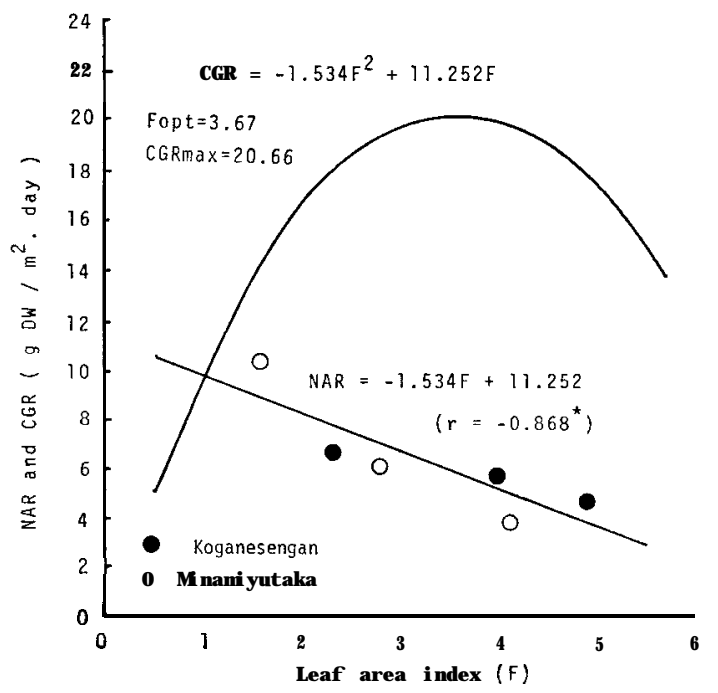

Fig. 4. Relations of leaf area index to net assimilation rate (NAR) and crop growth rate (CGR) during the period from July 22 to September 4, 1979. Fopt : optimum leaf area index, CGRmax : maximum crop growth rate. *Significant at 5 \% Ievel.

Table 3. Correlation coefficients of crop growth rate (CGR) with leaf area index (LAI) and net assimilation rate (NAR) at the first half and the second half of growth period.

\begin{tabular}{ccccc}
\hline \multirow{2}{*}{ Items } & \multicolumn{2}{c}{ The first half period } & \multicolumn{2}{c}{ The second half period } \\
\cline { 2 - 4 } & $\begin{array}{c}\text { Mean air } \\
\text { temperature }\end{array}$ & $\begin{array}{c}\text { Mean solar } \\
\text { radiation }\end{array}$ & $\begin{array}{c}\text { Mean air } \\
\text { temperature }\end{array}$ & $\begin{array}{c}\text { Mean solar } \\
\text { radiation }\end{array}$ \\
\hline CGR & $0.955^{* * *}$ & $0.850^{* *}$ & 0.494 & $0.927^{* *}$ \\
LAI & $0.843^{* *}$ & $0.732^{*}$ & 0.524 & 0.436 \\
NAR & 0.646 & $0.761^{*}$ & 0.445 & $0: 927^{* *}$ \\
\hline
\end{tabular}

$* \overline{\text { Significant at }} 5 \%, * *$ significant at $1 \%, * * *$ significant at $0.1 \%$ level.

latter showed a curvilinear one. From the curvilinear regression between LAI and CGR, it was calculated that CGRmax and Fopt were $20.66 \mathrm{~g} \mathrm{DW} / \mathrm{m}^{2}$ per day and 3.67, respectively. These values were slightly larger than those reported by Tsuno and Fujise (1965), but they were smaller than those reported by Kodama et al. (1971).

To make clear the differences of influence of LAI and NAR on CGR in the first and second half periods, it was necessary to analyze regarding the climatic factors. Among climatic factors, the mean air temperature and mean solar radiation are considered to be main factors affecting on CGR. The results of these analyses are given in Table 3 .

In two cultivars, CGR in the first half period correlated more highly with air temperature rather than with solar radiation. On the other hand, CGR in 
the second half period showed highly significant correlation only with solar radiation. Further, LAI in the first half period correlated highly with air temperature and NAR in the second half correlated with solar radiation. These results indicate that CGR in the first and second half periods are determined mainly with LAT through air temperature and with NAR through solar radiation, respectively. In addition, these relations were verified by the partial correlation analysis as shown in Table 4.

Table 4. Partial correlation coefficients of climatic factors to crop growth rate (CGR) at the first half and the second half of growth period.

\begin{tabular}{ccccc} 
& \multicolumn{2}{c}{ The first half period } & \multicolumn{2}{c}{ The second half period } \\
\cline { 2 - 5 } Items & $\begin{array}{c}\text { Mean air } \\
\text { temperature }\end{array}$ & $\begin{array}{c}\text { Mean solar } \\
\text { radiation }\end{array}$ & $\begin{array}{c}\text { Mean air } \\
\text { temperature }\end{array}$ & $\begin{array}{c}\text { Mean solar } \\
\text { radiation }\end{array}$ \\
\hline CGR & $0.847 * *$ & 0.307 & 0.410 & $0.919 * *$ \\
\hline
\end{tabular}

$* *$ Significant at $1 \%$ level.

\section{Relation between tuberous root growth rate and growth parameters}

In the case of sweet potatoes, tuberous root production is equal to yield. Therefore, the growth rate of tuberous root (yield growth rate, YGR) is one of the most important growth parameters.

As shown in Fig. 3, variation of YGR during the growth period was similar to that of CGR. However, the difference between CGR and YGR became smaller after August, and YGR exceeded CGR after the middle of October. Such a trend of Koganesengan was similar to that of Minamiyutaka. This fact indicates the translocation of reserved substances from other organs to tuberous roots in this term.

Table 5 shows the correlation coefficient of YGR with climatic factors and growth parameters obtained from two cultivars. It is obvious that YGR correlated more highly with CGR and NAR than LAI and that correlated closely with solar radiation. These results indicate that YGR is strongly influenced by solar radiation through NAR and CGR under the presence of LAI above optimum value.

Table 5. Correlation coefficients of tuber growth rate (YGR) with climatic factors and growth parameters.

\begin{tabular}{cccccc}
\hline & \multicolumn{2}{c}{ Climatic factors } & \multicolumn{3}{c}{ Growth parameters } \\
\cline { 2 - 6 } Items & $\begin{array}{c}\text { Mean air } \\
\text { temperature }\end{array}$ & $\begin{array}{c}\text { Mean solar } \\
\text { radiation }\end{array}$ & CGR & LAI & NAR \\
YGR & 0.403 & $0.893^{\prime \prime \prime}$ & $0.973^{* * *}$ & 0.527 & $0.950^{* * *}$ \\
\hline
\end{tabular}

**Significant at $1 \%$ level.

Lastly, effects of mean air temperature and mean solar radiation on CGR and YGR in the second half period were analyzed by multiple regressive 
method. The following equations were obtained;

$$
\begin{aligned}
& \mathrm{CGR}=-13.544+0.116 s-0.356 t\left(\boldsymbol{R}=\boldsymbol{O} .939^{* *}\right), \\
& \mathrm{YGR}=-6.119+0.096 \mathrm{~s}-0.447 \boldsymbol{t}\left(\boldsymbol{R}=\boldsymbol{O} .926^{* *}\right),
\end{aligned}
$$

where $\mathrm{s}$ and $t$ are mean solar radiation and mean air temperature, respectively. And $\boldsymbol{R}$ is multiple correlation coefficient. These results are also shown in Fig. 5. From the equations, it is obvious that solar radiation has a positive influence on CGR and YGR and that, on the contrary, air temperature acts negatively on them. These facts indicate that higher solar radiation and lower air temperature, within favourable range of growing temperature, are good for production of dry matter and yield during the second half period.

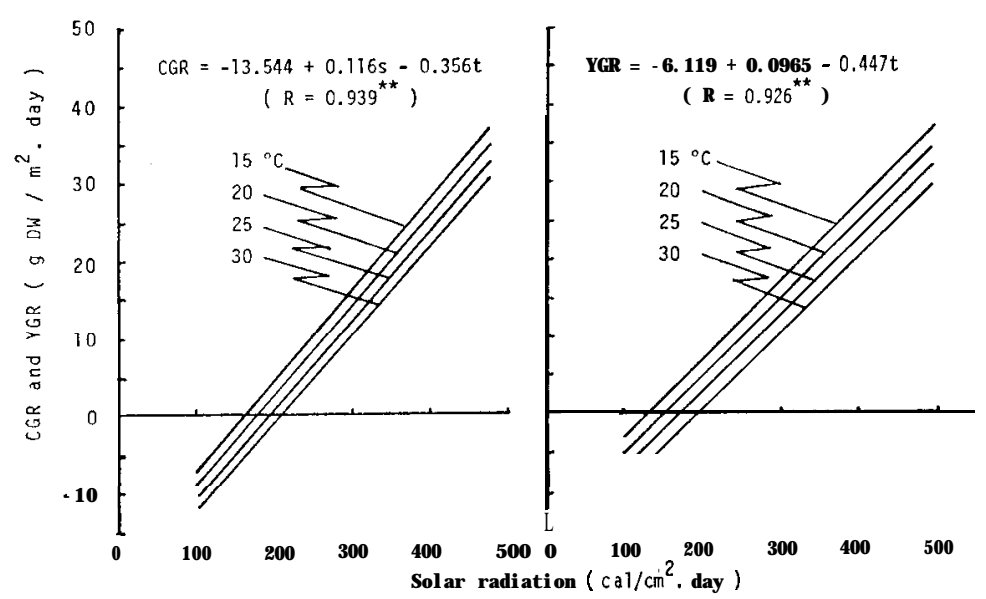

Fig. 5. Effects of solar radiation (s) and air temperature ( $t$ ) on crop growth rate (CGR) and tuberous root growth rate (YGR) in the second half of growth period. The analysis was made by mixed data of Koganesengan and Minamiyutaka.

The relation between total yield $(Y)$ and factors controlling it is shown by the following equation;

$$
Y=T \times \mathrm{YGR},
$$

where $\boldsymbol{T}$ is the growth period of tuberous root and YGR is growth rate of yield. According to the equation, yield is determined by both factors of $\boldsymbol{T}$ and YGR. Therefore, it is very important for the yield production of sweet potatoes to increase both $\boldsymbol{T}$ and YGR. As $\boldsymbol{T}$ and YGR are mainly determined by air temperature and solar radiation, respectively, the re-examination of climatic factors at each region is necessary for improvement of cultivation method of sweet potatoes.

\section{ACKNOWLEDGEMENT}

The authors wish to thank Dr. T. Sakamoto, the Kyushu National Agricultural Experiment Station, for providing the nursery stocks of sweet potatoes. 


\section{REFERENCES}

Boysen-Jensen, P. 1932 Die Stoffproduktion der Pflanzen. Fisher, Jend.

Buttery, B. B. 1969 Analysis of the growth of soybeans as affected by plant population and fertilizer. Can. J. Plant Sci., 49: 675-684

Donald, C. M. 1962 In search of yield. J. dust. Inst. Agr. Sci.. 28; 171-178

Donald, C. M. 1963 Competition among crop and pasture plants. Advances in Agronomy, 15: $1-118$

Kodama. S., K. Chuman and M. Tanoue 1971 On the growth differentials of sweet potato to different soil fertility. Bull. Kyushu Agr. Exp. Sta., 15: 493-514

Murata. Y. 1961 Studies on the photosynthesis of rice plants and its culture significance. Bull. Nat. Inst. Agr. Sci., D 9: 1-170

Nakaseko, K. and K. Gotoh 1981 Comparative studies on dry matter production, plant type and productivity in soybean, azuki bean and kidney bean. (111) Dry matter production of soybean plant at various population densities. Japan. J. Crop Sci.. 50: 47-53

Takeda, T. 1961 Studies on the photosynthesis and production of dry matter in the community of rice plants. Jap. J. Bot., 17: 403-437

Tateno. K. and M. Ojima 1973 Growth analysis of grain sorghum as affected by planting density and amount of nitrogen. Proc. Crop Sci. Soc, Japan, 42: 555-559

Tsuno, Y. and K. Fujise 1965 Studies on the dry matter production of sweet potato. Bull. Nat. Inst. Agr. Sci.. D 13: 1-131

Watson, D. J. 1952 The physiological basis of variation in yield. Advances in Agronomy, 4: 101-145 